\title{
Isolated Rectal Perforation Presenting as Peritonitis in a Child with Enteric Fever
}

\author{
Digamber Chaubey ${ }^{1} \quad$ Ajay Kumar Verma $^{1}$ Anand Pandey ${ }^{1} \quad$ Archika Gupta $^{1}$ \\ ${ }^{1}$ Department of Pediatric Surgery, King George's Medical University, \\ Lucknow, Uttar Pradesh, India \\ J Child Sci 2017;7:e120-e122. \\ Address for correspondence Anand Pandey, MCh, Department of
Pediatric Surgery, King George's Medical University, Lucknow
226003, Uttar Pradesh, India (e-mail: dranand27@rediffmail.com).
}
Abstract
Keywords
- typhoid
- perforation
- fever
- rectal perforation

Typhoid fever is common in developing countries. It may lead to bowel perforation. Terminal ileum is the most frequent site of perforation. However, perforation at uncommon sites such as rectosigmoid junction may occur occasionally. In this study we report a patient who we treated for perforation peritonitis; on exploratory laparotomy, it turned out to be a rectal perforation. The patient was operated successfully. As an unusual presentation, it is being reported with a review of the relevant literature.

\section{Introduction}

Typhoid fever is caused by the gram-negative bacillus Salmonella typhi (S. typhi), and it is an important public health problem in developing countries. ${ }^{1}$ Typhoid fever is endemic in those parts of world where sanitation is poor. ${ }^{2}$ Perforation of the bowel from typhoid fever is a serious abdominal complication, which continues to be the most frequent cause of its high morbidity and mortality. ${ }^{3}$ Terminal ileum is the commonest site of perforation. ${ }^{2}$ We treated a patient with a positive Widal's test and perforation in the anterior rectal wall.

\section{Case Report}

A 3-year-old girl presented with abdominal distension, peritonitis, and shock. She had fever for about 3 weeks and was prescribed some medications with remission of fever. One week later, the patient was readmitted for vomiting and diarrhea. She was admitted for about 10 days. During her stay, she was diagnosed with typhoid fever.

After 5 days of her stay, she developed abdominal pain and hematochezia, followed by abdominal distension. Abdominal X-ray in erect view was suggestive of pneumoperitoneum. She was referred to our center. At the time of admission, the patient was in hypovolemic shock. Her abdomen was distended. Per rectal revealed stool mixed with blood. The pulse rate was $130 /$ minute, respiratory rate was 28/minute, and blood pressure was 76/60 $\mathrm{mm} \mathrm{Hg}$. Hemoglobin was $6.3 \mathrm{~g} \%$, total leucocyte count was $20,800 / \mathrm{mm}^{3}$, packed cell volume was $26 \%$, serum $\mathrm{Na}^{+}$was 120 , and serum $\mathrm{K}^{+}$was $2.65 \mathrm{Meq} / \mathrm{L}$, respectively. The Widal's test was highly positive (typhi-O, 1:160; typhi-H, 1:320). Ultrasonography of abdomen was suggestive of mild splenomegaly, moderate ascites, and right-sided pleural effusion.

The patient was resuscitated with nasogastric decompression, urethral catheterization to monitor urine output, and intravenous fluids for fluid replacement. Packed red blood cells were transfused after proper grouping and cross-matching. A blood sample was taken for culture. After about 20 hours of admission, exploratory laparotomy was performed under general anesthesia. There was fecal contamination of the peritoneum. When we carefully inspected whole of the small and large bowel, the rectum was found to be inflamed, edematous, and covered with flakes. There was a single perforation of approximately $1.0 \mathrm{~cm}$ size in the anterior wall of the rectum (-Fig. 1). The mesenteric nodes were enlarged. After a thorough peritoneal lavage, a biopsy was taken from the perforation, and the perforation was closed primarily. Peritoneal fluid was sent for culture and sensitivity.

In the immediate postoperative period, the patient was treated with ceftriaxone $(70 \mathrm{mg} / \mathrm{kg} / \mathrm{day}$ intravenously [IV] 12 hourly), metronidazole ( $30 \mathrm{mg} / \mathrm{kg} /$ day IV every 8 hourly), and amikacin ( $15 \mathrm{mg} / \mathrm{kg} /$ day IV). Blood culture did not show the presence of any organism. Peritoneal fluid culture received

June 15, 2017

accepted after revision

August 6, 2017
DOI https://doi.org/

$10.1055 / \mathrm{s}-0037-1606571$. ISSN 2474-5871.

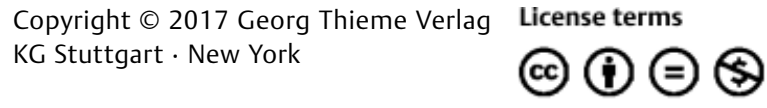




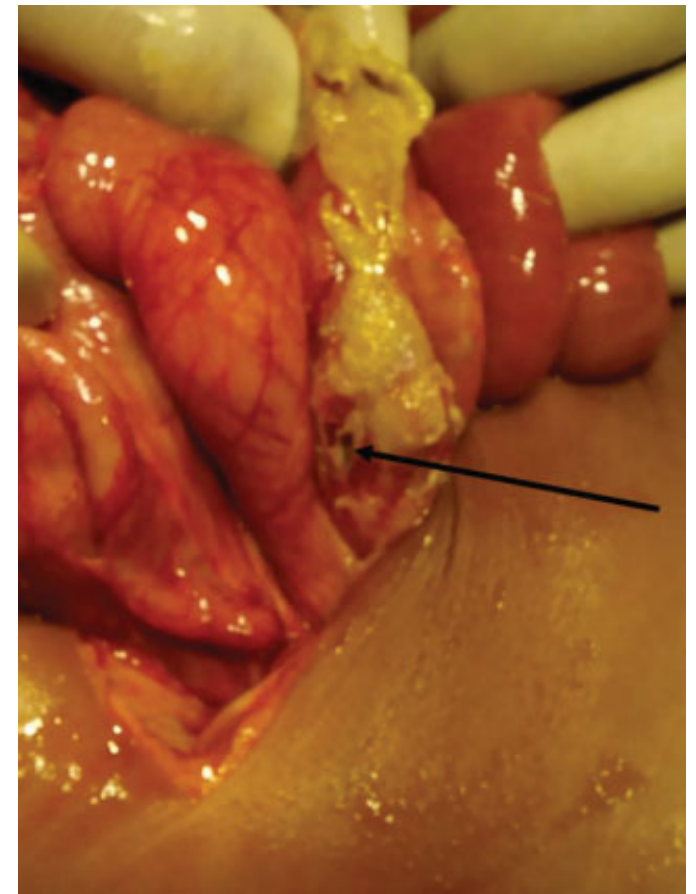

Fig. 1 Intraoperative photo showing rectal perforation (arrow pointing at the site of perforation).

sensitivity showed growth of Escherichia coli resistant to ceftriaxone but sensitive to meropenem. Hence, she was switched over to meropenem ( $20 \mathrm{mg} / \mathrm{kg} /$ day IV 8 hourly). The postoperative period was uneventful. The patient was allowed oral sips on the sixth postoperative day. She was discharged in satisfactory condition on the 10th postoperative day. The rectal biopsy histopathology showed pan mural inflammatory changes with ischemic colitis. The patient was followed up for 3 months. She did not have any problem.

\section{Discussion}

Typhoid fever is a major public health problem in developing countries. ${ }^{4}$ The infection is transmitted by the fecal-oral route and may occasionally lead to an epidemic, particularly in areas with poor sanitation and limited availability of clean, potable water. ${ }^{5}$ The frequency of perforation varies between 0.8 and $18 \%{ }^{6}$ Intestinal perforation in typhoid fever has reported mortality rates ranging between 20 and $60 \%$ in the developing countries. ${ }^{7}$

In areas endemic for typhoid fever and perforation, studies have shown that children younger than 15 years account for more than $50 \%$ of the intestinal perforation cases. These patients have higher mortality than the adults. ${ }^{7}$ These mortality data are for the ileal perforation; however, there have been studies of colonic perforation due to typhoid fever without any mortality. ${ }^{8}$ The involvement of colorectum in complications of typhoid perforation is very uncommon.

It is to be noticed that nontyphoid Salmonella and Clostridium may also be responsible for perforation; hence, proper investigations may be needed..$^{9}$ A plain abdominal radiograph can be an adjuvant when there is a high-index of suspicion for colon perforation in children with abdominal distention and history of fever or diarrhea for more than 5 days. ${ }^{9}$

Pathologically, S. typhi involves the Peyer's patches, which are present in the jejunum and ileum, and reach up to the cecum, ascending colon and up to left colon. ${ }^{8}$ We feel that the presence of ileocecal valve causes more exposure of ileum to infected bowel content as compared with the colon; hence, the likelihood of colon getting involved in complications of typhoid is less as compared with ileum. However, the exact cause of rectal involvement is not clear.

The standard diagnostic modality for typhoid fever is blood culture. ${ }^{10}$ However, it is to be noticed that the possibility of a positive culture decreases ${ }^{10}$ with the passage of time. This may be the reason for negative culture report in our patient, as patient presented in the third week of illness. Though Widal's test is not the test of choice, it has been observed that it has a very high negative predictive value, that is, negative Widal's test rules out the possibility of typhoid fever. ${ }^{11}$ Our patient had a positive test; hence, we believe that despite negative blood culture, it was a case of typhoid fever. This has also been observed by other investigators. ${ }^{8}$ Typhoid fever may involve hepatobiliary system besides the bowel. ${ }^{12}$ Besides ileum, which is the most common site of perforation, other reported sites are gall bladder, colon, and the rectum. ${ }^{12,13}$ However, these are very uncommon. Rectal perforation due to typhoid fever is even rarer with occasional reports. ${ }^{13}$

There has been an interest in laparoscopic repair of the perforation with peritonitis. However, it has been only reported in the adult population. ${ }^{14}$ Though laparoscopy has been used in children with certain conditions such as pyloric stenosis ${ }^{15}$ and a selected case of blunt and penetrating abdominal trauma, ${ }^{16}$ its use in pediatric perforation with peritonitis is not clear at present.

To conclude, though ileum is the commonest site of perforation, large bowel, including the rectum, may also be involved. Hence, in case of perforation due to typhoid fever, the whole of the small and large bowel, including rectum needs to be explored.

\section{Conflict of Interest}

None.

\section{References}

1 Crump JA, Luby SP, Mintz ED. The global burden of typhoid fever. Bull World Health Organ 2004;82(05):346-353

2 Pandey A, Gangopadhyay AN, Upadhyaya VD. Typhoid sigmoid colon perforation in an 18-month-old boy. World J Pediatr 2008;4 (04):305-307

3 Sharma A, Sharma R, Sharma S, Sharma A, Soni D. Typhoid intestinal perforation: 24 perforations in one patient. Ann Med Health Sci Res 2013;3(Suppl 1):S41-S43

4 Pujar KA, A C A, H K R, H C S, K S G, K R S. Mortality in typhoid intestinal perforation-a declining trend. J Clin Diagn Res 2013;7 (09):1946-1948

5 Chalya PL, Mabula JB, Koy M, et al. Typhoid intestinal perforations at a University teaching hospital in Northwestern Tanzania: 
A surgical experience of 104 cases in a resource-limited setting. World J Emerg Surg 2012;7:4

6 Sümer A, Kemik O, Dülger AC, et al. Outcome of surgical treatment of intestinal perforation in typhoid fever. World J Gastroenterol 2010;16(33):4164-4168

7 Osifo OD, Ogiemwonyi SO. Typhoid ileal perforation in children in Benin city. Afr J Paediatr Surg 2010;7(02):96-100

8 Chang YT, Lin JY, Huang YS. Typhoid colonic perforation in childhood: a ten-year experience. World J Surg 2006;30(02):242-247

9 Chang YJ, Yan DC, Kong MS, Chao HC, Huang CS, Lai JY. Nontraumatic colon perforation in children: a 10-year review. Pediatr Surg Int 2006;22(08):665-669

10 Wain J, Diep TS, Ho VA, et al. Quantitation of bacteria in blood of typhoid fever patients and relationship between counts and clinical features, transmissibility, and antibiotic resistance. J Clin Microbiol 1998;36(06):1683-1687

11 Andualem G, Abebe T, Kebede N, Gebre-Selassie S, Mihret A, Alemayehu H. A comparative study of Widal test with blood culture in the diagnosis of typhoid fever in febrile patients. BMC Res Notes 2014;7:653

12 Pandey A, Gangopadhyay AN, Kumar V. Gall bladder perforation as a complication of typhoid fever. Saudi J Gastroenterol 2008; 14(04):213

13 Abantanga FA, Nimako B, Amoah MA. Perforations of the Gut in Children as a Result of Enteric Fever-A 5-Years Single Institutional Review. Ann Pediatr Surg 2009;5(01):1-10

14 Ramachandran CS, Agarwal S, Dip DG, Arora V. Laparoscopic surgical management of perforative peritonitis in enteric fever: a preliminary study. Surg Laparosc Endosc Percutan Tech 2004;14 (03):122-124

15 Hendrickson RJ, Yu S, Bruny JL, Partrick DA, Petty JK, Bensard DD. Early experience with laparoscopic pyloromyotomy in a teaching institution. JSLS 2005;9(04):386-388

16 Feliz A, Shultz B, McKenna C, Gaines BA. Diagnostic and therapeutic laparoscopy in pediatric abdominal trauma. J Pediatr Surg 2006; 41(01):72-77 